\title{
The Effectiveness of High Quality Supplementary Cementitious Materials for Mitigating ASR Expansion in Concrete with High Alkali Content
}

\author{
Irfan Prasetia \\ Department of Civil Engineering \\ Faculty of Engineering, Lambung Mangkurat University \\ Banjarmasin, Indonesia \\ iprasetia@unlam.ac.id
}

\begin{abstract}
Alkali silica reaction (ASR) is influenced by external factors such as the surrounding environment of high alkalinity. Countries with cold climate have a high probability to be exposed to high concentrations of $\mathrm{NaCl}$ solution by the deicing salt. This condition will lead to serious ASR problems in concrete, if the aggregates contain reactive silica. The main research work in this paper is to investigate the effect of $15 \%$ replacement ratio of high quality fine fly ash (FA15\%) and $42 \%$ replacement ratio of blast furnace slag (BFS42\%) on the ASR mitigation in concrete with different alkali amount inside the pore solution. The experiments were conducted according to the accelerated mortar bars experiment following the JIS A1146 mortar bar test method. In addition, post-analysis such as observation of ASR gel formation by the Uranyl Acetate Fluorescence Method and observation of thin sections using a Polarizing Microscope were also conducted. The mortar bar tests show a very good mitigation effect of supplementary cementitious materials (SCMs). The results show that only small ASR expansions, which can be categorized as "innocuous", occurred for specimens with $1.2 \% \mathrm{Na}_{2} \mathrm{Oeq}$ using FA15\% and BFS42\%. However, larger alkali amount inside the system will require more SCMs amount.
\end{abstract}

Keywords-ASR expansion; alkali content; SCMs

\section{INTRODUCTION}

Alkali silica reaction (ASR) is influenced by internal factors such as alkali, aggregates contain reactive silica and moisture. Besides that, ASR is also influenced by external factors such as the surrounding environment condition and the use of the structures. In terms of reactive aggregates, in Hokuriku district, Japan, there are records that show that the reactive crushed andesite stone has been used throughout the Noto Peninsula. The serious ASR problems with a rupture of the reinforcing bar were also found on the Noto expressway and the national highway Route 249. Moreover, in the Joganji river in Toyama Prefecture, in the Tedori river in Ishikawa Prefecture, and in aggregate production from the basin of the river on top of the Kuzuryu river in Fukui Prefecture, the andesite particles contained in river sand and/or gravel show a high reactivity. In addition, the Hokuriku district has a lot of local companies that make PC Girder and PCa Product.
Furthermore, in the district of cold climate such as the Hokuriku and the Tohoku, which are heavy snow areas, the opportunity to be exposed to high concentrations of $\mathrm{NaCl}$ solution by the deicing salt has been increasing. Since 1982, ASR has been noticed in some highway structures in Hokuriku district by deicing salts. Besides promoting the ASR expansion, chloride penetrates to the concrete through the cracks caused by ASR expansion will also promote corrosion of the rebar thus will lead to complex degradation in concrete structures [1-2]. The combination of these inside and outside factors result to large numbers of ASR-affected PC bridge girders produced in the construction site or in the concrete factory discovered all over the nation by the recent survey of the Japan Concrete Institute on ASR Mitigation [3].

For this reason, in the Hokuriku district and also all over Japan, long-life PC bridges is becoming one of the important issues. So far, the high durability PC girders have been produced by using high fineness blast furnace slag powder (6000 Blaine value) [4]. However, the production sites of blast furnace slag powder are limited in the metropolitan and suburbs area such as Tokyo, Osaka, Nagoya and Kitakyushu. On the other hand, the Hokuriku district, such as Toyama, Ishikawa and Fukui, has coal-fired power plants in each prefecture. Thus, the effective utilization of fly ash in concrete mixture has become a new regional challenge. It becomes more important to expand the use of fly ash in concrete to establish the supply system and stabilize the quality. In addition, there was a history that concrete from the manufacturer had been avoided to be used in this district.

In order to solve this problem, in January 2011, the committee for promotion of effective utilization of fly ash to concrete in Hokuriku district, chaired by Prof. Kazuyuki Torii (Kanazawa University), has been launched. An active work of preparing a manual of fly ash concrete and stabilizing the supply of high quality fly ash had just started [5].

In line with that, in the works of Thomas, et al., interesting facts about fly ash can be found [6-8]. The test program, included both laboratory and field studies, showed that fly ash can be considered to contribute no alkalis when it is used at 
a $25 \%$ level (or bellow) of replacement with flint sands. This replacement ratio also could control ASR expansion even when the alkalis contributed by the portland cement component of the mixture are sufficient to cause ASR expansion in the absence of fly ash.

The main research work in this chapter is to investigate the effect of high quality fine fly ash (FA) on the ASR mitigation in concrete with different alkali amount inside the pore solution. In addition, samples with additional high quality fine blast furnace slag (BFS) were also prepared to compare the ASR mitigation effect between fly ash and BFS. Regarding the replacement ratios, $15 \%$ replacement ratio of FA and $42 \%$ replacement ratio of BFS were selected. The replacement ratio of FA was set at $15 \%$ is due to in Japan this replacement ratio is the lowest replacement ratio of FA for ASR mitigation in concrete according to JISA5308. As for BFS, 42\% level of BFS replacement ratio is the replacement ratio being used for blast-furnace slag mix cements type B which is the popular BFS cement in Japan. In addition, Japan's researcher commonly used these replacement ratios in experimental studies [9-11]. Moreover, the andesite aggregate from Hokkaido, Japan was used as the reactive aggregate and the accelerated mortar bars experiment will be conducted according to the JIS A1146 mortar bar test method.

\section{EXPERIMENTS}

\section{A. Materials}

Ordinary portland cement (OPC), from T Co, Ltd., (density: $3.16 \mathrm{~g} / \mathrm{cm}^{3}$, Blaine specific surface area: $3300 \mathrm{~cm}^{2} / \mathrm{g}$ ) was used. In order to investigate the effectiveness of SCMs on ASR mitigation, two types of SCMs were used. First is a high quality fly ash (FA) manufactured from Nanao Ohta coal fired power plant, I-type fly ash classified by JIS A6201, (density: $2.44 \mathrm{~g} / \mathrm{cm}^{3}$, Blaine specific surface area: $4780 \mathrm{~cm}^{2} / \mathrm{g}$, Ig.loss: $2.0 \%)$. Second is a high quality fine blast furnace slag fine powder (BFS) manufactured by S Co. Ltd (density: $2.91 \mathrm{~g} / \mathrm{cm}^{3}$, Blaine specific surface area: $6030 \mathrm{~cm}^{2} / \mathrm{g}$, Ig.loss $1.0 \%$ ). The chemical compositions of fly ash and blast furnace slag powder are shown in Table I.

As for the reactive andesite, two kinds of Hokkaido andesite, crushed andesite stone (G) and crushed andesite sand (S), were selected with particle size arranged from $0.15 \mathrm{~mm}$ to $5.0 \mathrm{~mm}$. The alkali silica reactivity of these aggregates were assessed "deleterious" by chemical tests according to JIS A1145 (Sc: $688 \mathrm{mmol} / 1, \mathrm{Rc}: 78 \mathrm{mmol} / \mathrm{l}, \mathrm{Sc} / \mathrm{Rc}=8.8$ ) which are higher compared to Hokuriku andesite which has Sc: 529 mmol/l and Rc: $119 \mathrm{mmol} / \mathrm{l}$. The Hokkaido andesite was also assessed as "deleterious" according to the JIS A1146 mortar bar test method. The reactive components of Hokkaido andesite were cristobalite, tridymite and little glass phases.

TABLE I CHEMICAL COMPOSITIONS OF FA AND BFS (\%)

\begin{tabular}{|c|c|c|c|c|c|c|c|c|c|c|}
\hline Mat. & $\mathbf{S i O}_{2}$ & $\mathbf{A l}_{2} \mathbf{O}_{3}$ & $\mathbf{F e}_{2} \mathbf{O}_{3}$ & $\mathbf{C a O}$ & $\mathbf{M g O}$ & $\mathbf{T i O}_{2}$ & $\mathbf{M n O}$ & $\mathbf{S O}_{3}$ & $\mathbf{N a}_{2} \mathbf{O}$ & $\mathbf{K}_{2} \mathbf{O}$ \\
\hline FA & 53.6 & 28.9 & 6.7 & 3.2 & 0.8 & 1.4 & 0.1 & 0.2 & 0.3 & 0.7 \\
\hline BFS & 33.0 & 13.6 & 0.1 & 42.6 & 5.8 & 0.6 & 0.2 & 3.1 & 0.2 & 0.2 \\
\hline
\end{tabular}

\section{B. Mix Proportions}

In this study, mortar bar specimens were prepared according to JIS A1146 test method. Three mix proportion were prepared, which are OPC, $15 \%$ replacement ratio of FA (FA15\%), and $42 \%$ replacement ratio of BFS (BFS42\%). Water to binder ratio (W/B) was set at $50 \%$. In each mix proportion, sodium hydroxide solution $(\mathrm{NaOH})$ was added for making the total alkali content equal to $1.2 \%$ and $2.4 \%$. The dimension of mortar bar specimens is $40 \times 40 \times 160 \mathrm{~mm}$. The mixture proportions of mortar bars specimens are listed in Table II.

The name of each specimen is described as in this orders:

1. Two numbers at the font are indicating the alkali amount inside the specimens.

2. The first letter afterwards is showing the aggregate which are crushed andesite stone $(\mathrm{G})$ or crushed andesite sand $(\mathrm{S})$.

3. The letter after that is referred to the mix proportions which are ordinary portland cement (OPC), $15 \%$ of high quality fine fly ash (FA15\%) or $42 \%$ of high quality blast furnace slag (BFS42\%).

\section{Test Methods}

\section{1) Accelerated Expansion Test}

The cement, fly ash and blast furnace slag powder are containing different forms of alkali and also have different effect on the ASR [12]. Thus, to investigate the effect of SCMs on the ASR mitigation in concrete with different alkali amount, the addition of $\mathrm{NaOH}$ solution was given to adjust the alkali content with equivalent amounts of $1.2 \%$ and $2.4 \% \mathrm{Na}_{2} \mathrm{Oeq}$. Mortar bar specimens were cured in fog chamber with a temperature of $40^{\circ} \mathrm{C}$, and more than $95 \%$ of relative humidity. Length change was measured at $20^{\circ} \mathrm{C}$. In JIS A1146, if the expansion ratio is over $0.05 \%$ for 3 months or over $0.1 \%$ for 6 months indicates "deleterious".

\section{2) ASR Gel Observation}

After the completion of accelerated mortar bar test, $0.1 \mathrm{~N}$ silver nitrate solutions was sprayed on the mortar fractured surface, to observe the formation of ASR gel by the uranyl acetate fluorescence method. The ASR gel shows a greenishyellow coloration area on the cutting surface of the specimens.

TABLE II MIXTURE PROPORTIONS OF MORTAR BARS SPECIMENS

\begin{tabular}{|c|c|c|c|c|c|c|c|c|}
\hline \multirow[b]{3}{*}{ No } & \multirow{3}{*}{$\begin{array}{l}\text { Specimen } \\
\text { Type }\end{array}$} & \multicolumn{7}{|c|}{ Unit amount for 3 specimens (gr) } \\
\hline & & \multirow[b]{2}{*}{ Water } & \multirow[b]{2}{*}{$\mathrm{NaOH}^{*}$} & \multirow[b]{2}{*}{ Cement } & \multirow[b]{2}{*}{$\begin{array}{l}\text { Fly } \\
\text { Ash }\end{array}$} & \multirow[b]{2}{*}{ BFS } & \multicolumn{2}{|c|}{ Aggregate } \\
\hline & & & & & & & \begin{tabular}{|c}
$\begin{array}{c}\text { Crushed } \\
\text { andesite } \\
\text { sand }\end{array}$ \\
\end{tabular} & \begin{tabular}{|c|} 
Crushed \\
andesite \\
stone
\end{tabular} \\
\hline \multirow{3}{*}{1} & $1.2 \mathrm{GOPC}$ & 174.2 & 3.9 & 600 & - & - & 1350 & - \\
\hline & $1.2 \mathrm{GFA} 15 \%$ & 189.9 & 3.4 & 510 & 90 & - & 1350 & - \\
\hline & $1.2 \mathrm{GBFS} 42 \%$ & 164.7 & 4.2 & 348 & - & 252 & 1350 & - \\
\hline \multirow{3}{*}{2} & $1.2 \mathrm{SOPC}$ & 174.2 & 3.9 & 600 & - & - & - & 1350 \\
\hline & $1.2 \mathrm{SFA} 15 \%$ & 189.9 & 3.4 & 510 & 90 & - & - & 1350 \\
\hline & $1.2 \mathrm{SBFS} 42 \%$ & 164.7 & 4.2 & 348 & - & 252 & - & 1350 \\
\hline \multirow{3}{*}{3} & $2.4 \mathrm{GOPC}$ & 228.4 & 2.2 & 600 & - & - & 1350 & - \\
\hline & 2.4 GFA $15 \%$ & 231.5 & 2.1 & 510 & 90 & - & 1350 & - \\
\hline & $2.4 \mathrm{GBFS} 42 \%$ & 226.5 & 2.3 & 348 & - & 252 & 1350 & - \\
\hline \multirow{3}{*}{4} & $2.4 \mathrm{SOPC}$ & 228.4 & 2.2 & 600 & - & - & - & 1350 \\
\hline & 2.4 SFA $15 \%$ & 231.5 & 2.1 & 510 & 90 & - & - & 1350 \\
\hline & $2.4 \mathrm{SBFS} 42 \%$ & 226.5 & 2.3 & 348 & - & 252 & - & 1350 \\
\hline
\end{tabular}




\section{3) Polarizing Microscope Observation}

After the end of the expansion test, polished thin section samples with $20 \mu \mathrm{m}$ thickness were prepared from each mortar bar specimen. The samples were observed to determine ASR gel and cracking by polarizing light microscopy. Classification of ASR deterioration using thin section was carried out according to the procedure shown in Table III with the reference of Katayama studies [13-14].

\section{RESULTS}

\section{A. Expansion Results}

1) Mortar Bars Using Crushed Andesite Stone

The expansion ratio results of mortar bar specimens using crushed andesite stone as the reactive aggregate can be seen in Figure 1. The expansion ratio of OPC samples tends to be larger in accordance with the addition of alkalis inside. Starting from the early stage, the ASR rate was very fast which is completed in 4 weeks. At the end of the measurement, the expansion ratio of $1.2 \mathrm{GOPC}$ is over 0.15 and the expansion ratio of $2.4 \mathrm{GOPC}$ is over $0.55 \%$. Thus, these results can be classified as "deleterious".

TABLE III PETROGRAPHIC CLASSIFICATION OF ASR SEVERITY STAGES

\begin{tabular}{|c|l|}
\hline Stages & \multicolumn{1}{c|}{ The Progress and Severity of ASR } \\
\hline I & $\begin{array}{l}\text { The formation of reaction rims and exudation of ASR sol/gel } \\
\text { around the reacted aggregate }\end{array}$ \\
\hline II & The formation of ASR gel-filled cracks within reacted aggregate \\
\hline III & $\begin{array}{l}\text { The propagation of ASR gel-filled cracks }(\max <25 \mu \mathrm{m}) \text { from } \\
\text { the reacted aggregate into surrounding cement paste }\end{array}$ \\
\hline IV & $\begin{array}{l}\text { The formation of ASR gel-filled cracks }(\max 25-50 \mu \mathrm{m}) \text { network } \\
\text { and the migration of ASR gel into air voids }\end{array}$ \\
\hline V & $\begin{array}{l}\text { The formation of ASR gel-filled cracks }(\max 50 \mu \mathrm{m}<) \text { network } \\
\text { and the migration of ASR gel into air voids }\end{array}$ \\
\hline
\end{tabular}

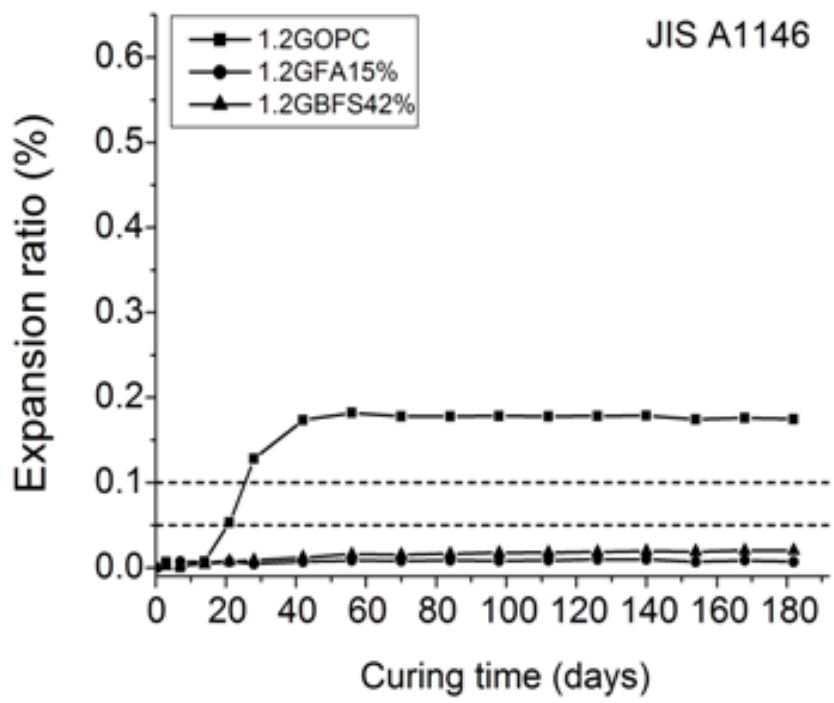

(a) specimens with $1.2 \% \mathrm{Na}_{2} \mathrm{Oeq}$
In the contrary, specimens with $\mathrm{FA} 15 \%$ and $\mathrm{BFS} 42 \%$ are still enough to mitigate ASR expansion with $1.2 \% \mathrm{Na}_{2} \mathrm{Oeq}$. However, the expansion becomes larger with the addition of alkali amount. The expansion ratio rose significantly within the span of three months and only a slight increase in expansion could be measured afterwards. In addition, it could be noted that $15 \%$ of fly ash replacement ratio and $42 \%$ of blast furnace slag replacement ratio are showing the same mitigation effect. The expansion ratio patterns are similar. At the end of the measurement, the expansion ratio was much smaller compared to OPC specimens. Overall, after six months, the expansion ratio of $1.2 \mathrm{GFA} 15 \%$ and $1.2 \mathrm{GBFS} 42 \%$ are below $0.05 \%$ which can be categorized as "innocuous". Whilst, the expansion ratio of $2.4 \mathrm{GFA} 15 \%$ and $2.4 \mathrm{GBFS} 42 \%$ are over $0.35 \%$ both of which can be categorized as "deleterious".

\section{2) Mortar Bars Using Crushed Andesite Sand}

As for expansion ratio results of mortar bar specimens using crushed andesite sand as the reactive aggregate can be seen in Figure 2. The expansion ratio results and ASR rates were showing the same pattern with mortar bars using crushed andesite stone. These results show that crushed andesite stone and crushed andesite sand aggregate have the same level of reactivity. This might also occur due to the same particle size. In general, ASR expansion is completed in just 4 weeks for OPC specimens, and around 12 weeks for specimens using FA and BFS.

After six months, the expansion ratio of $1.2 \mathrm{SOPC}$ is over $0.14 \%$ and the expansion ratio of $2.4 \mathrm{SOPC}$ is over $0.44 \%$, which these results can be classified as "deleterious". In addition, the expansion ratio of $1.2 \mathrm{SFA} 15 \%$ and $1.2 \mathrm{SBFS} 42 \%$ are below $0.05 \%$ which can be categorized as "innocuous" and the expansion ratio of $2.4 \mathrm{SFA} 15 \%$ and $2.4 \mathrm{SBFS} 42 \%$ are over $0.3 \%$ both of which can be categorized as "deleterious".

Fig. 1. Expansion ratio of mortar bar specimens using crushed andesite stone aggregate 


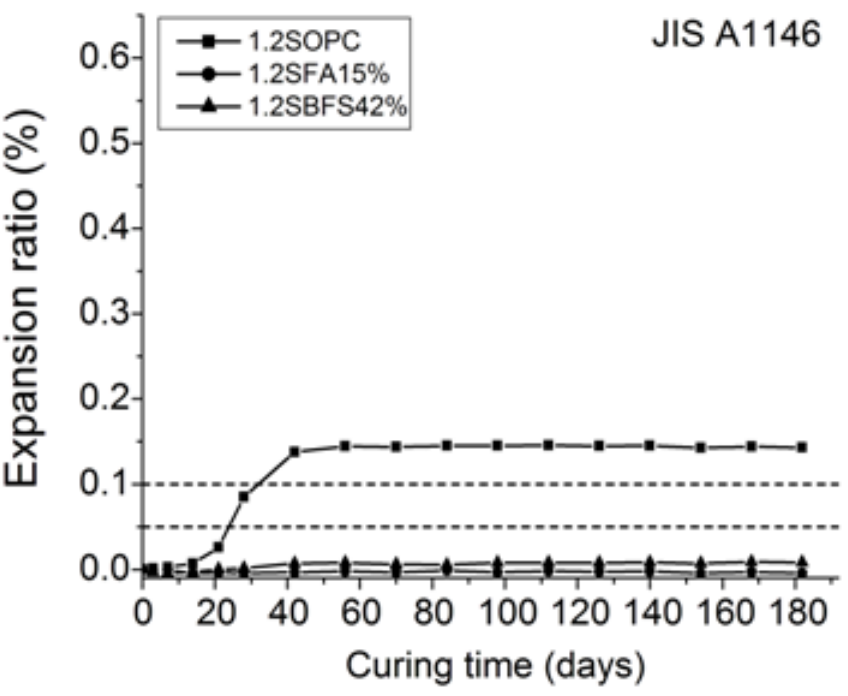

(a) specimens with $1.2 \% \mathrm{Na}_{2} \mathrm{Oeq}$

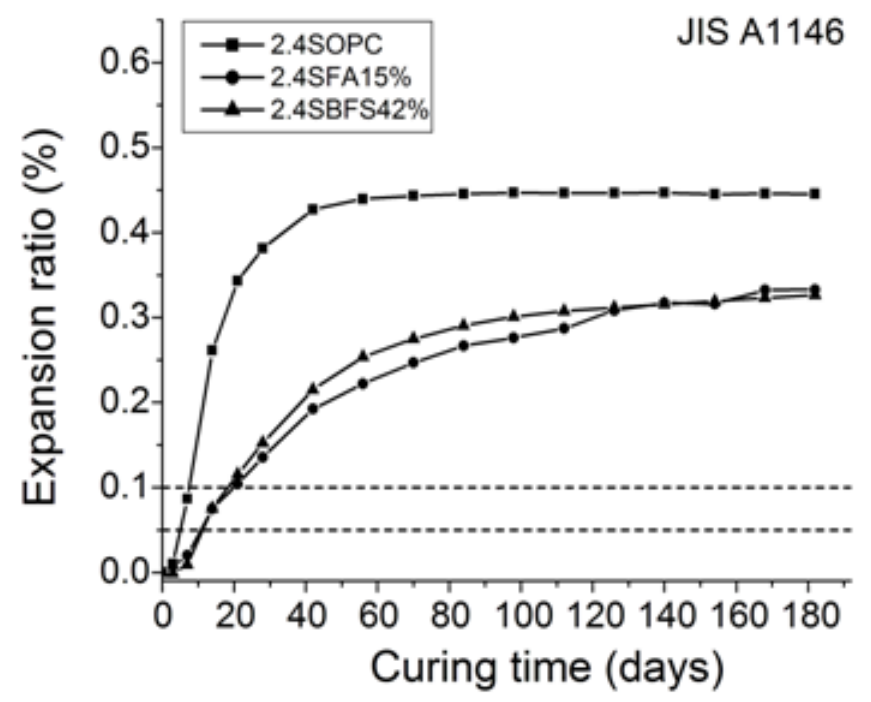

(b) specimens with $2.4 \% \mathrm{Na}_{2} \mathrm{Oeq}$

Fig. 2. Expansion ratio of mortar bar specimens using crushed andesite sand aggregate

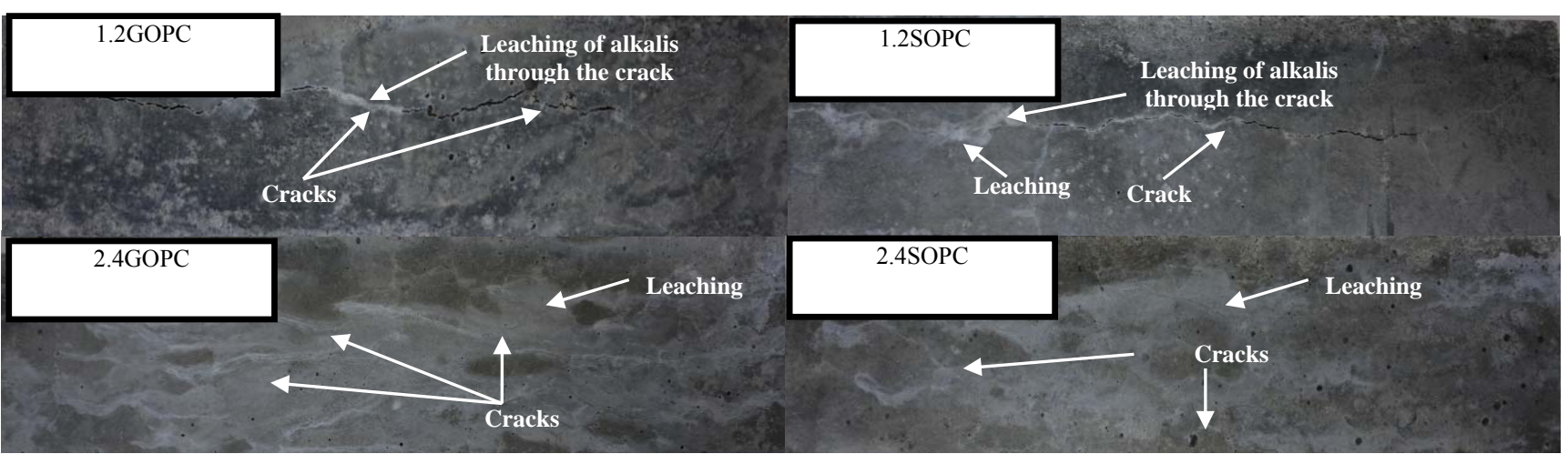

Fig. 3. Surface of OPC specimens with $1.2 \%$ and $2.4 \% \mathrm{Na}_{2} \mathrm{Oeq}$

3) Visual observation of specimen's surface

The surface of the OPC specimens with $1.2 \%$ and $2.4 \%$ $\mathrm{Na}_{2} \mathrm{Oeq}$ after completion of accelerated mortar bar test can be seen in Figure 3. In general, fine cracks begin to be visible when the expansions of the specimens reach the rate of $0.05 \%$ to $0.1 \%$. The progress of cracking of the specimen is in accordance with the increasing rate of expansion. For OPC specimens the cracks pattern observed started from the early stage. The cracks widths increased over time and begin to stop around 4 weeks afterwards. The cracks width is observed around $0.6 \mathrm{~mm}$ after the completion of accelerated mortar bar test. As for specimens with supplementary cementitious materials, fine cracks are observed from the second week of measurement. It was also observed that the increase of cracks width had stopped until the fourth week. However, the width of these cracks is much smaller compared with OPC specimens. The largest cracks width is found around $0.2 \mathrm{~mm}$.

Furthermore, beside cracks, leaching effects could also be observed on the surface of all specimens. Leaching effect was more visible on the specimens with higher alkali content. In addition, as for OPC specimens, the leaching effects could be seen on the early stage, while for the FA15\% and BFS42\% specimens could be observed at the latter stage. In general, this finding is in agreements with Thomas results that show that alkali leaching effect occurred in the smaller laboratory specimen [15]. The leaching effect might be the reason that the expansion of all specimens stopped after 4 weeks.

\section{B. ASR Gel Formation Observation}

After the JIS test method, uranyl acetate fluorescence method of coloring area was carried out to measure ASR gel formation. ASR gel observation was conducted to all specimens having large expansion (categorized as "deleterious" in JIS A1146 test method). The image of ASR gel observation of specimens with $2.4 \% \mathrm{Na}_{2} \mathrm{Oeq}$ is shown in Figure 4 .

Despite the large expansion of OPC specimens, only very few ASR gel could be observed. It was assumed that the ASR gel was extruded from the specimens. This is due to the leaching effects that occurred, as can be observed from the surface of the specimens. The ASR gel could almost not be seen in 1.2SOPC specimens. However, as the expansion 
became larger, the ASR gel could be easily observed, especially for specimens using crushed andesite sand aggregate

As for the FA15\% specimens, the ASR gel in 2.4GFA15\% and $2.4 \mathrm{SFA} 15 \%$ can be easily observed. Especially for the $2.4 \mathrm{SFA} 15 \%$ specimen, ASR gel could be seen on the inner section and outer section of the sample, although only a few ASR gel could be observed. Thus, these results are adding more confidence on the expansion test results. However, there was no ASR gel to be observed in BFS42\% specimens with $2.4 \% \mathrm{Na}_{2}$ Oeq. It is assumed that the leaching of alkalis and ASR gel was more pronounced in the BFS42\% specimens.

\section{Polarizing Microscopic Observation}

After the completion of accelerated mortar bar test, thin section observation of mortar bar specimens by polarizing microscope were also conducted. The results of Polarizing Microscopic observation of specimens with $2.4 \% \mathrm{Na}_{2} \mathrm{Oeq}$ is shown in Figure 5. The polarizing microscopic observations were conducted to the specimens that categorized as "deleterious".

In general, the observation of cracks widths, filled with ASR gels, are linier with the expansion result. In the specimens with larger expansion, wider cracks can be observed. In 2.4GOPC, there was observed continuous large cracks, filled with ASR gel, from the aggregate $(25 \mu \mathrm{m}$ until $50 \mu \mathrm{m})$ to the cement paste (ASR level: IV). As the expansion ratio decreased in the 2.4SOPC specimen, the cracks width decreased and became less then $25 \mu \mathrm{m}$ (ASR level: III). As for $1.2 \mathrm{GOPC}$ and 1.2 SOPC specimens, there was no progress of cracks to be observed from the aggregate to the cement paste (ASR level: II). This pattern could also be seen on specimens using supplementary cementitious materials. The largest cracks width can be observed in $2.4 \mathrm{GFA} 15 \%, 2.4 \mathrm{SFA} 15 \%, 2.4 \mathrm{GBFS} 42 \%$ and $2.4 \mathrm{SBFS} 42 \%$ specimens, which the cracks width are less than then $25 \mu \mathrm{m}$ (ASR level: III). Thus, these results confirm the expansion test results.

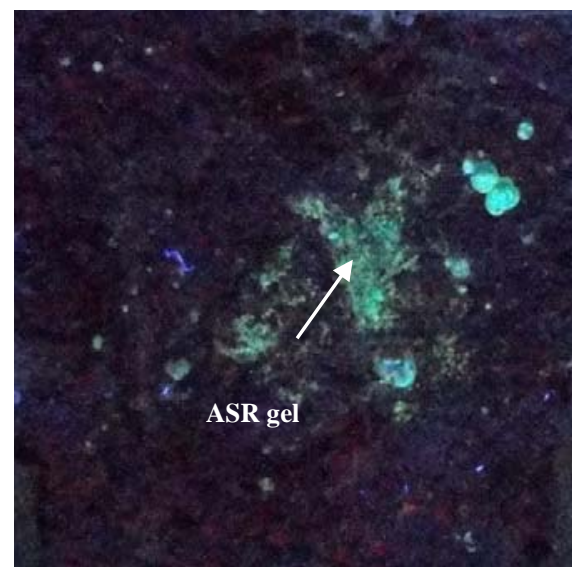

(a) OPC specimen

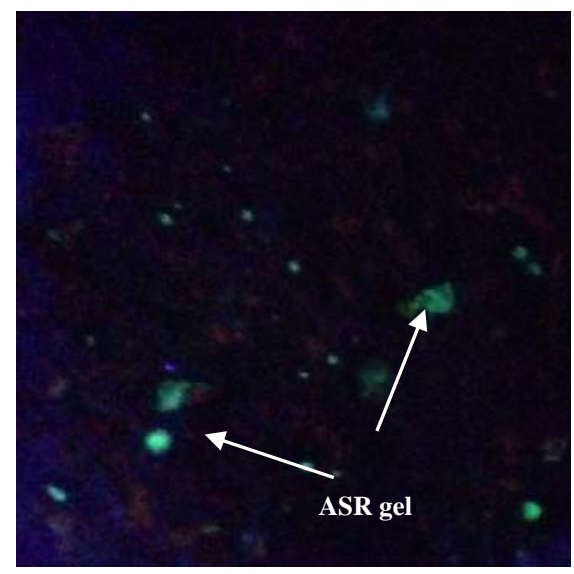

(b) FA15\% specimen

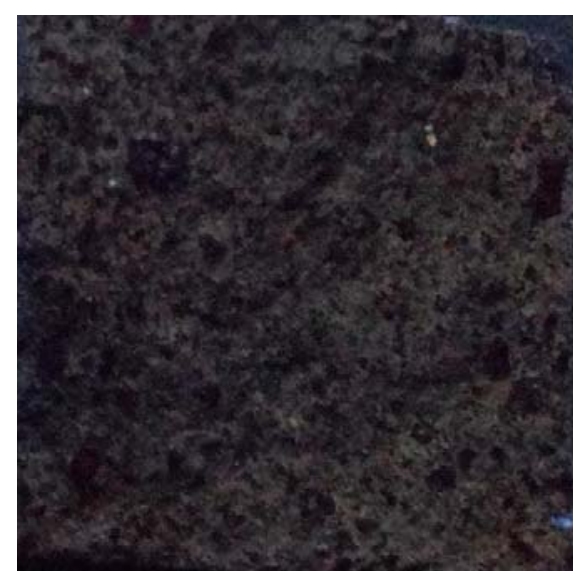

(c) BFS42\% specimen

Fig. 4. ASR gel formation observations of mortar bar specimens using crushed andesite sand aggregate with $2.4 \% \mathrm{Na}_{2} \mathrm{Oeq}$ by uranyl acetate fluorescence method (observed area: $40 \mathrm{~mm}$ x $40 \mathrm{~mm}$ )

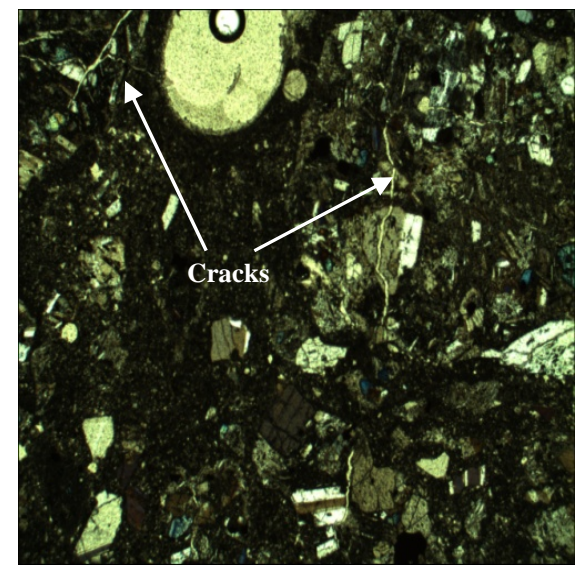

(a) OPC specimen

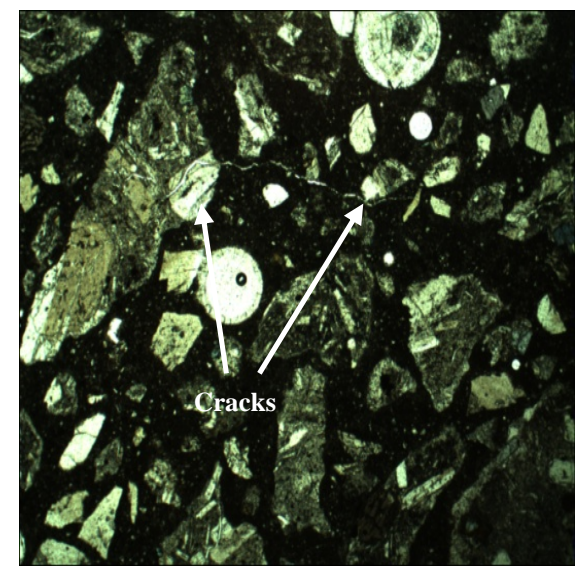

(b) FA15\% specimen

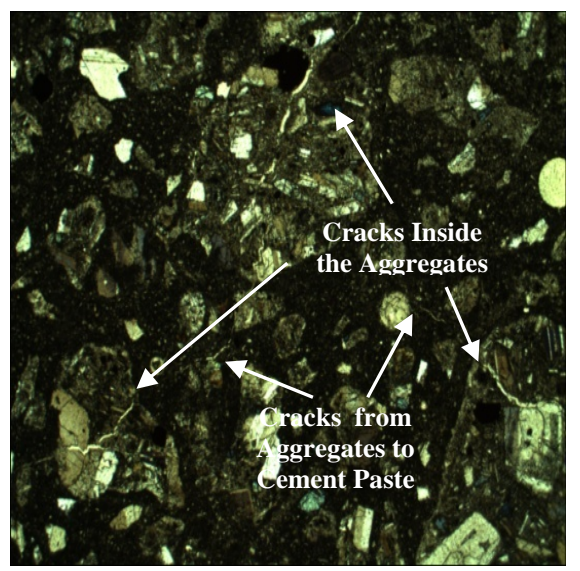

(c) $\mathrm{BFS} 42 \%$ specimen

Fig. 5. Polarizing Microscopic Observation of mortar bar specimens using crushed andesite sand aggregate with $2.4 \% \mathrm{Na}_{2} \mathrm{Oeq}$ by uranyl acetate fluorescence method (observed area: $40 \mathrm{~mm}$ x $40 \mathrm{~mm}$ ) 


\section{DisCUSSIONS}

The expansion ratios of all specimens using cement only (OPC) exceed $0.1 \%$ after 6 months regardless of their alkali amount. This result may verify the high reactivity of the crushed andesite stone and crushed andesite sand aggregates which are produce in Hokkaido. In addition, the results show that the larger alkali amount inside the system will also require larger replacement ratio of SCMs. In the effectiveness of fly ash and blast furnace slag on controlling ASR, the amount of fly ash and blast furnace slag needed is linear with the amount of alkalis inside the concrete. However, there is a maximum number of replacement ratios of fly ash and blast furnace slag that should be considered. Usually, the maximum number of replacement ratios of fly ash is until 35\% and until $60 \%$ for blast furnace slag. Exceeding the maximum replacement ratios will reduce the ultimate strength of concrete. Beside that, differences in the ASR mitigation effect will not be significant.

The mitigation effect of SCMs, can be attributed to the alkali binding capacity of SCMs. By adding fly ash or blast furnace slag in concrete, it can produce more CSH with a low ratio $\mathrm{Ca} / \mathrm{Si}$ produced from the pozzolanic reaction between fly ash or blast furnace slag and portland cement. Thus, there will be much more available alkalis that can bind to halt the ASR process. Moreover, the finer fly ash with an amorphous silica glass has higher pozzolanic reactivity. Thus, the alkali binding capacity is expected to be much significant with finer fly ash.

Furthermore, in the future, it is expected that the effect of the addition of high quality fly ash and blast furnace slag in concrete will be more significant. Especially in Hokuriku district, which has three coal-fired power plants in each prefecture, fly ash certainly becomes a valuable opportunity to overcome ASR problems that occurred.

\section{CONCLUSIONS}

The experiment works on investigating the mitigating effect of high quality fly ash and blast furnace slag on ASR expansion in accelerated mortar bar test with low and high alkali level have been conducted. The main concluding remarks obtained from the present research are summarized as follows:

(1) The accelerated mortar bars test confirms the high reactivity of Hokkaido's andesite aggregate. ASR expansion is completed in just 4 weeks for OPC specimens. However, it was delayed, around 12 weeks, for specimens using FA and BFS.

(2) The crushed andesite stone and crushed andesite sand aggregate have the same level of reactivity, which is high reactivity. This might occur due to the same particle size.

(3) The application of JIS A1146 made possible to determine the inhibitory effect of ASR of both FA and BFS powder especially in the early stages. The addition of $15 \%$ replacement ratio of $\mathrm{FA}$ and $42 \%$ replacement ratio of BFS could completely inhibit the ASR in specimens with $1.2 \% \mathrm{Na}_{2} \mathrm{Oeq}$.

(4) The required amount of SCMs to mitigate ASR depends on the alkali content inside the mortar bar specimens.
The larger alkali amount inside the system will require more SCMs amount.

(5) The alkali binding mechanism of $\mathrm{CSH}$, with a low ratio $\mathrm{Ca} / \mathrm{Si}$ produced from the pozzolanic reaction between $\mathrm{SCMs}$ and portland cement, give significant contribution in binding available alkali in the pore solution.

(6) In the future, it is expected that the effect of the addition of fly ash and blast furnace slag in concrete will be more significant in Hokuriku district.

\section{References}

[1] T. Habuchi, N. Miyasaka, H. Tsuji, K. Torii, "Evaluation of combined deterioration of concrete structures in marine environment due to alkalisilica reaction and seawater attack", 4th International Conference on Concrete under Severe Conditions, Vol. 2, pp. 2026-2033, 2004

[2] P. R. Vassie, "A secondary of ASR on bridges-corrosion of reinforcement steel", 2nd International Conference on Bridge Management, pp. 18-21, 1993

[3] K. Torii, "The Characteristic Feature of Fracture of Steel Reinforcement in ASR-Deteriorated Concrete Structures", Corrosion Engineering, Vol. 59, No. 4, pp. 59-65, 2010

[4] Japan Society of Materials Science, "Report on the development of prestressed concrete structures using high durability powder blast furnace slag", 1998 (in Japanese).

[5] K. Torii, "High durability of concrete through the use of fly ashApproach and information dissemination to ASR problem of Hokuriku region”, Civil Engineering in Electric Power, No. 357, pp. 11-15, 2012 (in Japanese).

[6] M. D. A. Thomas, B. Q. Blackwell, P. J. Nixon, "Estimating the alkali contribution from fly ash to expansion due to the alkali-aggregate reaction in concrete", Magazine of Concrete Research, Vol. 48, No. 177, pp. 251-264, 1996

[7] M. D. A. Thomas, B. Q. Blackwell, "Summary of BRE research on the use of fly ash to suppress AAR expansion", 10th International Conference on AlkaliAggregate Reaction in Concrete, pp. 554-61, 1996

[8] R. L. Hooper, J. D. Matthews, P. J. Nixon, M. D. A. Thomas, "The introduction of BS EN450 fly ash and mitigating the risk of ASR in the U.K.", 10th International Conference on Alkali-Aggregate Reaction in Concrete, Vol. 1, pp. 544-53, 2004

[9] T. Hashimoto, K. Torii, "The development of highly durable concrete using classified fine fly ash in Hokuriku district”, Journal of Advanced Concrete Technology, Vol. 11, pp. 312-321, 2013

[10] C. Sannoh, T. Hashimoto, K. Torii, "The suppressing effect of fly ash on asr under outdoor exposure conditions at the seashore", 3rd International Conference on Sustainable Construction Materials and Technologies, Kyoto, Japan, August 18-21, 2013

[11] T. Kanda, H. Momose, K. Yoda, A. Shintani, "Experimental investigation for improving shrinkage cracking resistance of BFS blended cement concrete exposed to hot environment", 3rd International Conference on Sustainable Construction Materials and Technologies, Kyoto, Japan, August 18-21, 2013

[12] Japan Concrete Institute., "Report of research committee and diagnostic suppression of alkali-aggregate reaction considering the mechanism of action”, pp. 68-81, 2008 (in Japanese).

[13] T. Katayama, M. Tagami, Y. Sarai, S. Izumi, T. Hira, "Alkali-aggregate reaction under the influence of deicing salts in the Hokuriku district, Japan”, Materials Characterization, Vol. 53, No. 2-4, pp. 105-122, 2004

[14] T. Katayama, T. Oshiro, Y. Sarai, K. Zaha, T. Yamato, "Late-expansive ASR due to imported sand and local aggregates in Okinawa Island, South western Japan", 13th International Conference on AlkaliAggregate Reaction in Concrete, pp. 862-873, 2008

[15] M. D. A. Thomas, B. Fournier, K. Folliard, J. Ideker, M. Shehata, "Test methods for evaluating preventive measures for controlling expansion due to alkali-silica reaction in concrete", Cement and Concrete Research, Vol. 36, No. 10, pp. 1842-1856, 2006 